\title{
Comparison of Laser Doppler Flowmetry and Thermometry in the Postoperative Monitoring of Replantations
}

\author{
Steven E. R. Hovius, MD, PhD, Léon N. A. van Adrichem, MD, PhD, \\ H. D. Mulder, MD, R. van Strik, DSt, J. C. van der Meulen, MD, PhD, \\ Rotterdam, The Netherlands
}

\begin{abstract}
Reliable postoperative monitoring in microvascular surgery is necessary to improve the success rate of reexplorations following vascular compromise. Surface thermometry is known as an easy and inexpensive objective postoperative monitor and therefore is used by many microsurgeons. Reliability, however, is not satisfactory, and therefore several other instrumental methods have been tested of which laser Doppler flowmetry shows the most promising results. This study compared laser Doppler flowmetry to thermometry in the postoperative monitoring after replantation surgery. In 34 patients, 45 replantations and revascularizations were monitored by laser Doppler flowmetry and thermometry. A reliable alarm value of $10 \mathrm{PU}$ was defined for replantations and revascularizations, with a sensitivity of $93 \%$ and a specificity of $94 \%$. Thermometry showed a sensitivity of $84 \%$ and a specificity of $86 \%$ at $29^{\circ} \mathrm{C}$. (J Hand Surg 1995;20A:88-93.)
\end{abstract}

The most feared complication in microvascular surgery is occlusion of anastomoses. Early recognition of this condition may prevent the loss of replanted or free vascularized tissue, as the blood flow can be restored by reconstructing the vascular anastomoses. It is essential to recognize the vascular compromise early, because the effectiveness of intervention is inversely related to the time that has

From the Department of Plastic and Reconstructive Surgery, University Hospital Dijkzigt and Department of Biostatistics of the University of Rotterdam, Rotterdam, The Netherlands.

Received for publication Oct. 22, 1992; accepted in revised form May 28, 1994.

Although the author or authors have not received or will not receive benefits for personal or professional use from a commercial party related directly or indirectly to the subject of this article, benefits have been or will be received but are directed solely to a research fund, foundation, educational institution, or other nonprofit organization with which one or more of the authors are associated.

Reprint requests: Dr. S. E. R. Hovius, University Hospital Dijkzigt, Department of Plastic and Reconstructive Surgery, Dr. Molewaterplein 40, 3015 GD Rotterdam, The Netherlands. elapsed between suspicion of vascular compromise and reexploration. ${ }^{1}$ Clinical judgment alone is not satisfactory, therefore several methods have been developed to monitor microcirculation or establish the patency of microvascular anastomoses. ${ }^{2-4}$

Postoperative monitoring should be objective, direct, noninvasive, reliable, continuous, easy, and inexpensive. The tissue surface thermometry is known as an easy and inexpensive postoperative monitor and therefore is used by many microsurgeons. Unfortunately, tissue temperature is easily influenced by the surroundings. Nevertheless, several authors have demonstrated enthusiasm for surface temperature measurements as a method of monitoring following microvascular surgery. ${ }^{5-8}$ The critical temperature, below which reexploration is indicated, should be $30^{\circ} \mathrm{C} .{ }^{9}$ Leonard and Brennen ${ }^{10}$ stated that two thermocouples should be used, one on the revascularized tissue and one on adjacent normal skin. A difference of $2^{\circ} \mathrm{C}$ between the two should indicate circulatory impairment.

Because thermometry is not always the ideal monitor in microvascular surgery, other methods 
have been studied. The most recent reports have been on laser Doppler flowmetry, and promising results were presented, although some predictions were false. ${ }^{11-17}$

Pietila et al. ${ }^{18}$ compared laser Doppler flowmetry and thermometry in the postoperative monitoring of replanted rabbit ears and concluded that the laser Doppler flowmeter was more sensitive to changes in capillary blood flow, but the reproducibility of the method was worse than that of thermometry. ${ }^{18}$

\section{Materials and Methods}

During the study period, 45 replantations and revascularizations were monitored in 34 patients. The mean age of the patients was 35 years (range, 7-62 years), and the male to female ratio was 32 to 2 . The patients were monitored by laser Doppler flowmetry and thermometry for 5 days postoperatively unless a reexploration was necessary. Following reintervention, patients reentered the study for another period of 5 days.

\section{Laser Doppler Flowmetry}

The laser Doppler flowmeter (Perimed KB, Järfälla Sweden) has been extensively described previously. ${ }^{19-23}$ Values obtained by laser Doppler flowmetry (LDF) are presented in perfusion units (PU).

LDF measurements were taken continuously at the same site, that is, the pulp skin of the distal phalanx. A probe holder was sutured to the skin so that the fiber optic cable was held continuously at a constant distance from the skin surface.

\section{Thermometry}

The surface temperature was measured by a thermocouple connected to a thermograph (Y.S.I. 44 TA, Yellow Springs, OH). Temperature is an indirect measurement of skin perfusion, which is influenced by the temperature of the deeper tissues and of the surroundings. The thermocouple was fixed by medical adhesive tape to the dorsal skin of the distal phalanx of the replanted digit (the same finger used for LDF monitoring), as well as a control digit in the same hand skipping, the adjacent digits when possible.

\section{Statistical Analysis}

The 5 days of monitoring were split into 24030 minute periods. Within every 30 -minute period the mean value of LDF measurements was obtained as well as a single skin temperature measurement and a difference in temperature between the control and replanted digit. For further analysis of each parame- ter, the lowest of the thus obtained values per recording was used.

Patients were divided into three groups, according to the clinical course, which was (1) uncomplicated, (2) compromised (e.g., hematoma, compression, vascular kinking), and (3) complicated by an arterial or venous occlusion.

For every parameter the two-tailed Mann-Whitney rank sum test was used to assess differences between the uncomplicated and vascular occlusion group. The Spearman rank correlation test was used to assess the strength of relationships between the different parameters. Analysis of sensitivity and specificity was performed. It was assumed that the 41 uncomplicated cases and the 10 cases with a vascular occlusion were representative for the relevant populations. The rankit score method was used to estimate the distributions of laser Doppler flow measurements within these relevant populations in order to calculate the sensitivity and specificity.

\section{Results}

In the 34 patients with 45 replantations or revascularizations, 52 recordings were made (Fig. 1).

All 52 laser Doppler recordings were complete, 4 temperature recordings of the replants were incomplete, and in 3 cases no reliable control temperature was measured.

The results of LDF monitoring are described in Figure 2 and Table 1. The results of thermometry recordings are displayed in Figures 3 and 4 and Table 1.

LDF and temperature were highly correlated (rho $=0.681 ; \mathrm{p}<.0001)$, as well as LDF and differential temperature (rho $=0.622 ; \mathrm{p}<.0001$ ). Also, temperature and differential temperature showed a high correlation (rho $=0.805 ; \mathrm{p}<.0001$ ). For comparison of LDF and thermometry, sensitivity and specificity curves were made for both monitoring methods for the studied group as well as for the total population (Figs. 5 and 6).

\section{Discussion}

The effectiveness of reintervention is inversely related to the time that has elapsed between the suspicion of vascular compromise and reexploration. ${ }^{1}$ Kerrigan et al. demonstrated in cutaneous island flaps in pigs that the secondary critical ischemic time for $90 \%$ flap survival (4.7 hours) was far less than the primary critical ischemic time ( 7.0 hours). ${ }^{24}$ Therefore, reintervention in clinically failing microvascular procedures should be as early as possible. The decision to reexplore on the basis of clinical judgment alone, even by experienced surgeons, has 


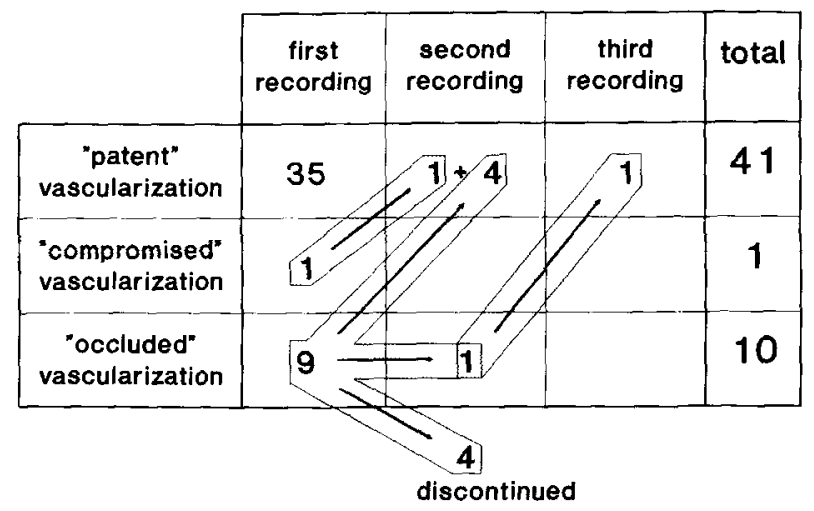

Figure 1. Fifty-two recordings in 34 patients with 45 replantations. Seven reexplorations were performed, and six were monitored postoperatively. No reexploration was performed in three cases. The difference in numbers between the recordings and replants was due to reentry of cases into the study following vascular compromise. During 41 recordings the course was uncomplicated, during, recording compromised (haematoma) and during 10 recordings a vascular occlusion occurred. The compromised replant was successfully reexplored and after removal of the haematoma the replant survived. In 9 replants a vascular occlusion occurred. Three patients were not reexplored; one patient suffered from respiratory problems, which were a contraindication for anaesthesia, and in two patients the vascular reconstruction was made on very small vessels, so that secondary reconstruction was technically impossible. In five patients a reexploration was performed; four reexplorations were successful and in one patient a reocclusion occurred, but a second reexploration saved the replant. One reexplored replantation could not be monitored due to lack of apparatus.

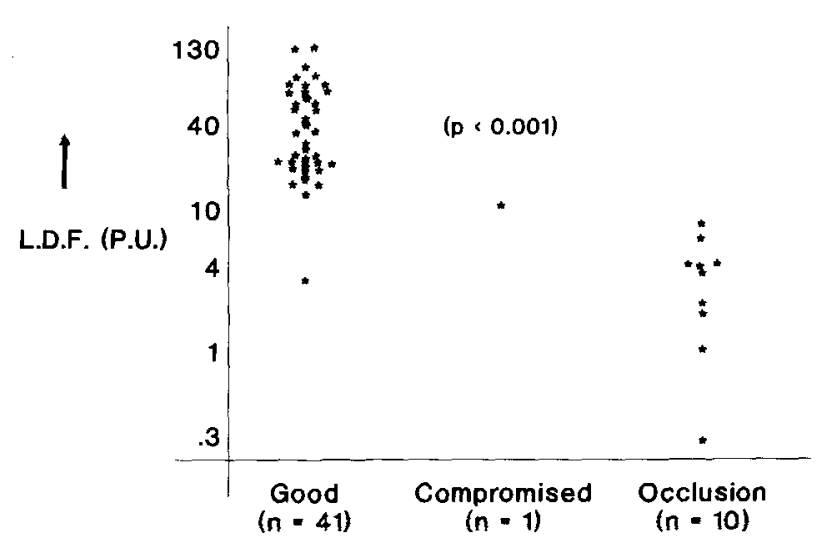

Figure 2. The lowest mean 30-minute LDF value of every replantation and revascularization registration is shown in this diagram on a logarithmic scale. The good cases ranged from 3.3 to $130 \mathrm{PU}$ (mean, $49 \mathrm{PU}$ ); in the compromised case the value was $10 \mathrm{PU}$, and the vascular occlusion cases ranged from .3 to $8.0 \mathrm{PU}$ (mean 3.7 PU). The difference between the good cases and vascular occlusion cases was significant $(\mathrm{p}<.001)$.

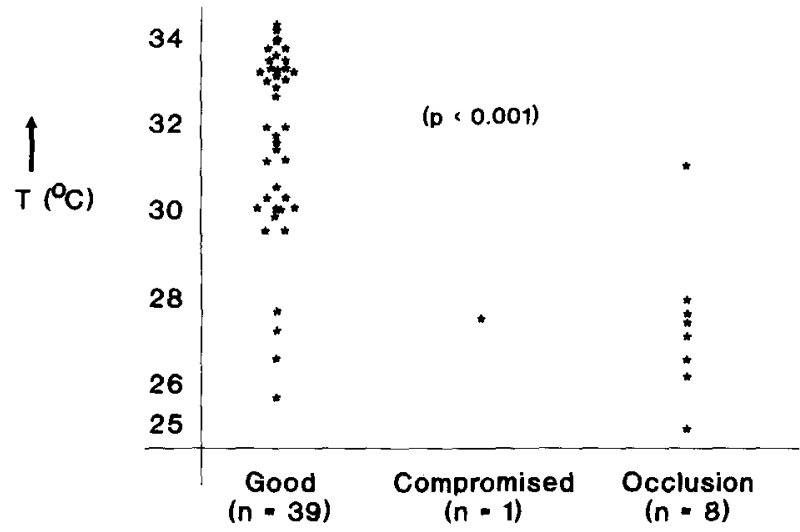

Figure 3. The lowest 30-minute temperature value of every replantation and revascularization registration is shown in this diagram. The good cases ranged from $25.6^{\circ}$ to $34.1^{\circ} \mathrm{C}$ (mean, $31.5^{\circ} \mathrm{C}$ ); in the compromised case the value was $27.5^{\circ} \mathrm{C}$, and the vascular occlusion cases ranged from $25.0^{\circ}$ to $31.0^{\circ} \mathrm{C}$ (mean, $27.2^{\circ} \mathrm{C}$ ). The difference between the good cases and vascular occlusion cases was significant $(\mathrm{p}<.001)$.

proven to result in considerable time loss and a high secondary failure rate of up to $60 \%$. This is especially valid during the night, when most failures tend to occur and experienced staff is not always present.

Thermometry has been used by many microvascular surgeons in postoperative monitoring because it is easy, inexpensive, and objective. False predictions, however, were made by this method, and a more nearly ideal monitor was researched. LDF seemed to be the most promising, although it is a

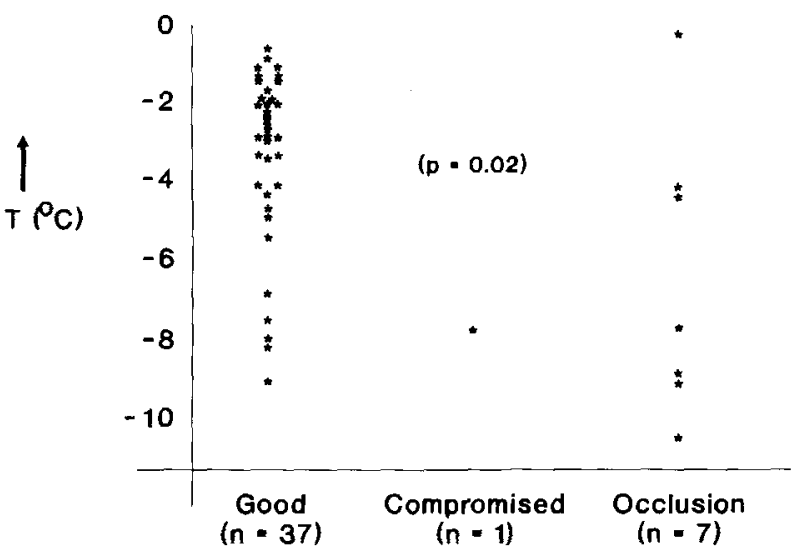

Figure 4. The lowest 30-minute differential temperature value of every replantation and revascularization registration is shown in this diagram. The good cases ranged from $-9.1^{\circ}$ to $-0.7^{\circ} \mathrm{C}$ (mean, $-3.4^{\circ} \mathrm{C}$ ); in the compromised case the value was $-7.7^{\circ} \mathrm{C}$, and the vascular occlusion cases ranged from $10.5^{\circ}$ to $-0.4^{\circ} \mathrm{C}$ (mean, $-6.5^{\circ} \mathrm{C}$ ). The difference between the good cases and vascular occlusion cases was significant $(\mathrm{p}=.02)$. 
Table 1. Laser Doppler Flow, Temperature, and Differential Temperature in 52 Recordings

\begin{tabular}{|c|c|c|c|c|c|c|c|c|}
\hline \multicolumn{3}{|c|}{ Patent Vascularization $(n=41)$} & \multicolumn{3}{|c|}{$\begin{array}{l}\text { Compromised Vascularization } \\
\qquad(n=1)\end{array}$} & \multicolumn{3}{|c|}{$\begin{array}{l}\text { Occluded Vascularization } \\
\qquad(n=10)\end{array}$} \\
\hline $\begin{array}{l}L D F \\
(P U)\end{array}$ & $\begin{array}{c}\text { Temp } \\
\text { (degrees) }\end{array}$ & $\begin{array}{c}\text { DiffT } \\
\text { (degrees) }\end{array}$ & $\begin{array}{l}L D F \\
(P U)\end{array}$ & $\begin{array}{c}\text { Temp } \\
\text { (degrees) }\end{array}$ & $\begin{array}{c}\text { DiffT } \\
\text { (degrees) }\end{array}$ & $L D F(P U)$ & $\begin{array}{c}\text { Temp } \\
\text { (degrees) }\end{array}$ & $\begin{array}{c}\text { DiffT } \\
\text { (degrees) }\end{array}$ \\
\hline 3.3 & 25.6 & -8.0 & 10.0 & 27.5 & -7.7 & 0.3 & 27.9 & -0.4 \\
\hline 12.0 & 32.6 & -3.4 & & & & 1.0 & 27.0 & -7.7 \\
\hline 13.0 & 27.2 & -7.5 & & & & 2.3 & & \\
\hline 13.3 & 26.5 & -8.3 & & & & 2.7 & 31.0 & -4.5 \\
\hline 16.0 & 30.2 & -4.7 & & & & 3.7 & & \\
\hline 16.7 & 29.5 & -5.5 & & & & 4.0 & 25.0 & -10.5 \\
\hline 16.7 & 32.8 & -2.8 & & & & 4.0 & 26.1 & -9.2 \\
\hline 16.7 & 33.2 & -2.3 & & & & 4.0 & 27.6 & \\
\hline 18.0 & 27.6 & -9.1 & & & & 6.7 & 27.5 & -4.2 \\
\hline 23.0 & 33.0 & -2.0 & & & & 8.0 & 26.5 & -8.9 \\
\hline 23.3 & 29.8 & -6.8 & & & & & & \\
\hline 23.3 & 30.5 & -3.5 & & & & & & \\
\hline 23.3 & 31.1 & -4.4 & & & & & & \\
\hline 23.3 & 33.1 & -3.1 & & & & & & \\
\hline 23.3 & 33.4 & -2.1 & & & & & & \\
\hline 26.7 & 30.0 & -5.0 & & & & & & \\
\hline 26.7 & 31.1 & -3.4 & & & & & & \\
\hline 28.0 & 30.0 & & & & & & & \\
\hline 33.3 & 30.0 & -3.0 & & & & & & \\
\hline 36.7 & 33.0 & -2.9 & & & & & & \\
\hline 36.7 & 33.2 & -2.0 & & & & & & \\
\hline 40.0 & 31.3 & -2.7 & & & & & & \\
\hline 43.3 & 33.8 & -1.4 & & & & & & \\
\hline 46.7 & 29.5 & -0.7 & & & & & & \\
\hline 46.7 & 30.2 & -4.2 & & & & & & \\
\hline 53.3 & 33.6 & -1.3 & & & & & & \\
\hline 53.3 & 34.0 & -1.4 & & & & & & \\
\hline 63.3 & 33.1 & -1.8 & & & & & & \\
\hline 66.7 & 33.9 & -1.5 & & & & & & \\
\hline 73.3 & 31.6 & & & & & & & \\
\hline 80.0 & 31.5 & -3.0 & & & & & & \\
\hline 80.0 & 31.9 & -2.4 & & & & & & \\
\hline 80.0 & 34.1 & -1.0 & & & & & & \\
\hline 86.7 & 29.9 & -4.2 & & & & & & \\
\hline 86.7 & 33.4 & -2.1 & & & & & & \\
\hline 86.7 & 33.7 & -1.5 & & & & & & \\
\hline 100.0 & 33.1 & -2.1 & & & & & & \\
\hline 100.0 & 33.7 & -1.3 & & & & & & \\
\hline 113.3 & & & & & & & & \\
\hline 130.0 & & & & & & & & \\
\hline 130.0 & 31.9 & -2.6 & & & & & & \\
\hline
\end{tabular}

The lowest value of monitoring Laser Doppler Flow (LDF), temperature (Temp), and differential temperature (DiffT) is given for all 52 postoperative replant monitoring periods divided into 3 groups, according to the clinical course.

rather expensive method and the microsurgeon requires knowledge of the method for proper use. This study shows that in the postoperative monitoring of replantations LDF is superior to thermometry in detecting vascular occlusions, although a false prediction was made by the LDF.

If one is not able to use LDF, thermometry is a reasonable alternative. In this study thermometry was monitored at the dorsal skin of the distal phalanx, in several cases dorsal and palmar temperature measurements were recorded without clear difference in temperature. Also, in experimental limb transplants in rats no difference was demonstrated in temperature recordings on different locations of the transplant ${ }^{25}$ It is therefore unlikely that the dorsal temperature measurements account for the difference in results between LDF and temperature in this study. Differential temperature measurements did not improve the sensitivity and specificity as was suggested by Leonard and Brennen, ${ }^{10}$ it was even 


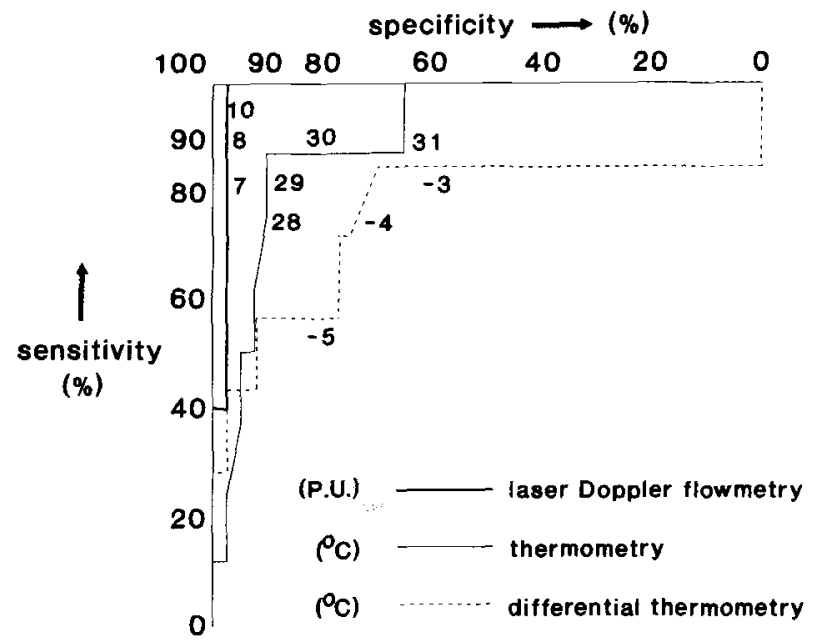

Figure 5. The sensitivity/specificity curves calculated from the studied group are shown for laser Doppler flowmetry, surface thermometry, and differential surface thermometry. The sensitivity/specificity curves are best for laser Doppler flowmetry, followed by temperature second and differential temperature as third.

inferior to measuring temperature of the replant only. If thermometry is used, one should only measure at the replanted digit.

The best alarm value of LDF (Perimed KB, Järfälla, Sweden) in replantation surgery seems to be 10 PU, with an estimated sensitivity of $93 \%$ and specificity of $94 \%$. If a microsurgeon is eager to save his

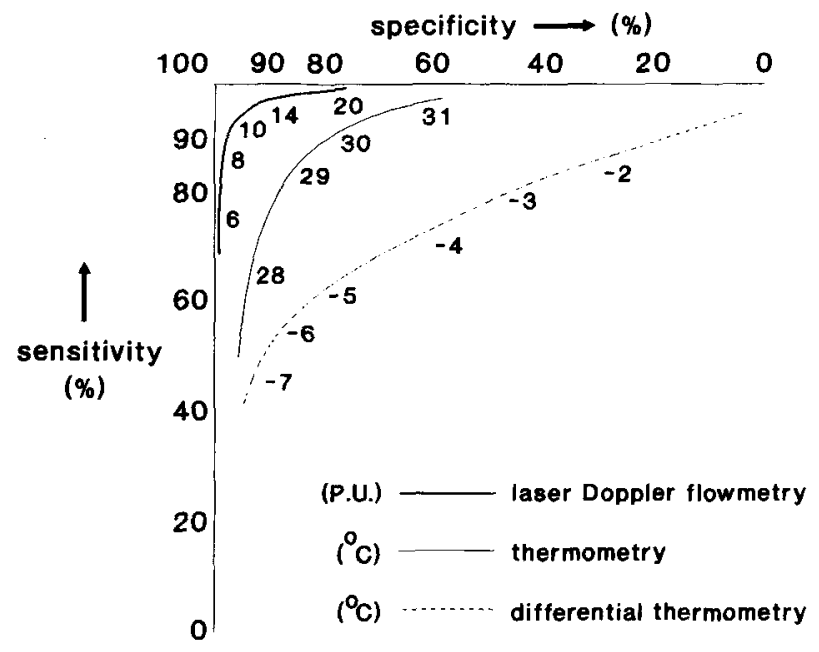

Figure 6. The sensitivity/specificity curves estimated for the total population are shown for laser Doppler flowmetry, surface thermometry, and differential surface thermometry. The sensitivity/specificity curves are best for laser Doppler flowmetry, followed by temperature second and differential temperature third. The best alarm value for surface thermometry is $29^{\circ} \mathrm{C}$ and for laser Doppler flowmetry 10 PU. replants and does not mind reexploring $10 \%$ of cases unnecessarily, then the alarm value may be 14 PU. Conversely, the microsurgeon only accepts reexploration of 1 of 100 replantations unnecessarily and accepts missing 4-5 of the 20 expected vascular occlusions, the alarm value may be $6 \mathrm{PU}$. In this study we would have recognized all 11 vascular occlusions on 52 LDF recordings and we would have reexplored 1 patient unnecessarily if we had depended on LDF with an alarm value of $10 \mathrm{PU}$.

LDF equipment is available from several companies; unfortunately the equipment is different in the laser type and signal processing. Therefore comparison of results of different equipment is difficult. The alarm values mentioned by us are unfortunately only valid for the Perimed apparatus. But some studies indicate that extrapolation of laser Doppler data is possible. ${ }^{26,27}$ Comparable results in postoperative monitoring in microvascular surgery using different apparatus were found by Clinton et al. ${ }^{17}$ and our group. ${ }^{16}$ Therefore, our main conclusion probably sustains for other LDF equipment.

The best alarm value of thermometry in replantation surgery seems to be $29^{\circ} \mathrm{C}$, with a sensitivity of $84 \%$ and a specificity of $86 \%$. This value is lower than the $30^{\circ} \mathrm{C}$ suggested by Stirrat et al. ${ }^{9}$

In the only false prediction of the LDF in this study, the temperature also gave a false prediction. Therefore, we do not expect improvement of sensitivity and specificity when combining LDF with thermometry.

\section{References}

1. Goodstein WA, Buncke HJ. Patterns of vascular island anastomoses vs. success of free groin flap transfers. Plast Reconstr Surg 1979;64:37-40.

2. Jones BM. Monitors for the cutaneous microcirculation. Plast Reconstr Surg 1984;73:843-50.

3. Harrison DH, Girling M, Mott G. Experience in monitoring the circulation in free-flap transfers. Plast Reconstr Surg 1981; 68:543-53.

4. Sloan GM, Sasaki GH. Noninvasive monitoring of tissue viability. Clin Plast Surg 1985;12:185-95.

5. Ackland RD. Experience in monitoring the circulation in free flap transfers (Discussion). Plast Reconstr Surg 1976;57:577.

6. Lister GD, Kleinert HE. Replantation. In: Grabb WC, Smith JW, eds. Plastic surgery. 3rd ed. Boston: Little, Brown, 1979:697-715.

7. Lister GD, Kalisman M, Tsai TM. Reconstruction of the hand with free microneurovascular toe-to-hand transfer: experience with 54 toe transfers. Plast Reconstr Surg 1983;71:372-86.

8. Okutsu I, Ninomiya, Takatori Y, Kuroshima N. Monitoring skin temperature in microvascular anastomosis. Orthop Rev 1982;11:39-42. 
9. Stirrat CR, Seaber AV, Urbaniak JR, Bright DS. Temperature monitoring in digital replantation. $J$ Hand Surg 1978;3:342-7.

10. Leonard AG, Brennen MD, Colville J. The use of continuous temperature monitoring in the postoperative management of microvascular cases. $\mathrm{Br} \mathrm{J}$ Plast Surg 1982;35:337-42.

11. Jones BM, Mayou BJ. The laser Doppler flowmeter for microvascular monitoring: a preliminary report. Br J Plast Surg 1982;35:147-9.

12. Svensson H, Pettersson H, Svedman P. The laser Doppler flowmetry and laser photometry for monitoring free flaps. Scand J Plast Reconstr Surg 1985;19: 245-9.

13. Heden PG, Hamilton R, Arnander C, Jurell G. Laser Doppler surveillance of the circulation of free flaps and replanted digits. Microsurgery 1985;6:11-9.

14. Walkinshaw M, Holloway A, Bulkley A, Engrav LH. Clinical evaluation of laser Doppler blood flow measurements in free flaps. Ann Plast Surg 1987;18: 212-7.

15. Jenkins S, Sepka R, Barwick WJ. Routine use of laser Doppler flowmetry for monitoring autologous tissue transplants. Ann Plast Surg 1988;21:423-6.

16. Hovius SER, van Adrichem LNA, Mulder HD, van Strik R, van der Meulen JC. The predictive value of the laser Doppler flowmeter for postoperative microvascular monitoring. Ann Plast Surg 1993;31:307-12.

17. Clinton MS, Sepka RS, Bristol D et al. Establishment of normal ranges of laser Doppler blood flow in autologous tissue transplants. Plast Reconstr Surg 1991; 87:299-309.
18. Pietila J, v Smitten K, Sundell B. The effect of perfusion on postoperative viability in the replanted rabbit ear: measured by laser Doppler flowmetry and skin temperature. Scand J Plast Reconstr Surg 1985;19: 251-4.

19. Riva C, Ross B, Benedek GB. Laser Doppler measurements of bloodflow in capillary tubes and retinal arteries. Invest Ophthalmol 1972;11:936-44.

20. Stern $\mathbf{M}$. In vivo evaluation of microcirculation by coherent light scattering. Nature 1975;254:56-8.

21. Holloway GA, Watkins DW. Laser Doppler measurement of cutaneous blood flow. J Invest Dermatol 1977;69:306-9.

22. Nilsson GE, Tenland TE, Oberg PA. Evaluation of a laser Doppler flowmeter for measurement of tissue blood flow. IEEE Trans Biomed Eng 1980;27: 597-604.

23. van Adrichem LNA. Laser Doppler flowmetry in microvascular surgery. Thesis, Erasmus University, Rotterdam, The Netherlands, 1992.

24. Kerrigan CL, Zelft RG, Daniel RK. Secondary critical ischemia time of experimental skin flaps. Plast Reconstr Surg 1984;74:522-4.

25. Hovius SER, van Adrichem LNA, van der Heijden PMA, Vusevski VD, van Strik R, van der Meulen JC. Postoperative monitoring of in allogeneic limb transplantation in rats. Ann Plast Surg 1988;21:559-65.

26. Fischer JC, Parker PM, Shaw WW. Comparison of two laser Doppler flowmeters for the monitoring of dermal blood flow. Microsurgery 1983;4:164-70.

27. Barnett NJ, Dougherty G, Pettinger SJ. Comparative study of two laser Doppler blood flowmeters. J Med Engineer Technol 1990;14:243-9. 